\title{
Missing, mediocre, or merely obsolete? An evaluation of UK data sources for coronary heart disease
}

\author{
B Unal, J A Critchley, S Capewell
}

J Epidemiol Community Health 2003;57:530-535

See end of article for authors' affiliations ......................

Correspondence to: Dr B Unal, Department of Public Health, Whelan Building, The Quadrangle, Liverpool University, Liverpool, UK; belgina@liv.ac.uk

Accepted for publication 3 November 2002

\begin{abstract}
Study objective: Coronary heart disease (CHD) is the commonest cause of death in the UK. However, there is no single comprehensive source of information to support CHD prevention and treatment strategies. Therefore this study evaluated the availability and quality of UK CHD data sources since 1981.

Design: Data sources for England and Wales were identified and appraised on:

(1) CHD patient numbers (myocardial infarction, angina, hypertension, and heart failure); (2) uptake of medical and surgical CHD treatments, and (3) population trends in major cardiovascular risk factors. Setting: England and Wales (population 53 million).

Main results: Population and mortality data were easily accessible from Office for National Statistics and British Heart Foundation Annual CHD Statistics; population based risk factor data came principally from the British Regional Heart Study, the General Household Survey, and the Health Survey for England. They were limited for 1981, but more extensive by 2000 . Hospital admissions information since 1998 was available online from HES; but trend data and details of interventions were scant. Limited primary care data on consultation rates, prescribing, and treatment uptake were available from published audits and studies.

Conclusions: Information on CHD in the UK is fragmented, patchy, and mixed in quality. Data for women, the elderly populatiom, and ethnic minorities were particularly scarce, exacerbating inequalities. Future CHD disease monitoring and evaluation will require comprehensive and accurate population based information on trends in patient numbers, treatment uptake, and risk factors.
\end{abstract}

$\mathrm{P}$ olicy decisions on health and health care increasingly require good evidence, particularly as resources are limited. ${ }^{1}$ Good evidence to describe the current situation means not just information on the effectiveness of interventions, but also valid and reliable data on the disease burden and the provision of health care.

Coronary heart disease (CHD) is the most common cause of death in the UK. CHD mortality rates have halved in most industrialised countries since the 1970s. However, mortality has declined less in the UK, and CHD still generates a massive burden of disease. ${ }^{23}$ To tackle this problem, the CHD National Service Framework (NSF) ${ }^{3}$ and the National Health Service (NHS) Plan have set national standards for prevention and treatment, and have recommended service models for efficient delivery of care, with milestones, goals, and early priorities. They also identified indicators and clinical audit criteria that could be used to assess the quality of care. ${ }^{4}$ Good health information is crucial for the implementation and monitoring of the CHD NSF. The recent CHD Information Strategy was therefore explicitly intended to support the CHD NSF by defining and establishing the information infrastructure, systems and services required. ${ }^{4}$ However, the Information Strategy did not comprehensively evaluate the sources of CHD information.

The aim of this study was therefore to evaluate the availability and quality of UK CHD data sources since 1981. This study explicitly considered all "public health" information sources for CHD, as defined in the recent Department of Health CHD Information Strategy. ${ }^{4}$ This included information on patterns of mortality and morbidity (including hospital admissions and episodes) and major cardiovascular risk factor trends by age, sex, and ethnicity.

\section{METHODS}

UK data sources on CHD were initially identified and categorised according to the IMPACT CHD mortality model, which aims to explore CHD mortality trends in England and Wales during 1981-2000. ${ }^{5}$ To build the IMPACT Model, information was required on (a) population based mortality rates; (b) patient numbers with different categories of CHD-acute myocardial infarction, unstable and chronic angina, heart failure, hypertension, coronary artery by pass graft (CABG) surgery, and angioplasty; (c) uptake of specific medical and surgical treatments; (d) effectiveness of specific cardiological treatments and risk factor reductions; and (e) population trends in major cardiovascular risk factors (smoking, cholesterol, hypertension, obesity, diabetes, physical activity, and deprivation).

Data were identified and obtained by various methods including comprehensive Medline search using keywords and MeSH headings, searching conference proceedings, audit reports, online search of possible official web sites, and personal correspondence (details available from authors).

The main data sources for population and mortality data were the Office for National Statistics (ONS) ${ }^{6}$ and the British Heart Foundation's Annual CHD Statistics. ${ }^{2}$ Information on treatment prescription and uptake were obtained from various national and local clinical audits ${ }^{7-9}$ and surveys. ${ }^{10-13}$ Data on efficacy of interventions and risk factor changes were reviewed from published randomised controlled trials, metaanalyses, and population studies.

The British Regional Heart Study, ${ }^{14}$ General Household Survey, ${ }^{15}$ and Health Survey for England ${ }^{16}$ were the main data sources for risk factor data.

Each data source was evaluated by two researchers using a standardised approach based on the following criteria: coverage and completeness (population of interest), coding accuracy (where these were reported in the primary data source), validity (the degree to which a variable measures what it purports to measure ${ }^{17}$ - where this was reported in the primary data source)—and generalisability (critical appraisal 
Table 1 Population and patient data sources of information on CHD in the UK, 1981-2000

\begin{tabular}{|c|c|c|}
\hline Information & Source & Evaluation \\
\hline Population statistics (1981-2000) (number) & Office for National Statistics ${ }^{18}$ & $\begin{array}{l}\text { Easily accessible, accurate, and up to } \\
\text { date }\end{array}$ \\
\hline Deaths by age and sex (1981-2000) (number) & $\begin{array}{l}\text { Available online from Office for National Statistics }{ }^{6} \text { and as } \\
\text { published reports } 66\end{array}$ & $\begin{array}{l}\text { Death certification complete, } \\
\text { standardised coding. Only minority } \\
\text { based on necropsy. May over estimate } \\
\text { CHD deaths in elderly people. }\end{array}$ \\
\hline CHD mortality (rates) & $\begin{array}{l}\text { Available as mortality statistics from Office for National } \\
\text { Statistics }{ }^{66} 67 \text { and from British Heart Foundation Annual } \\
\text { CHD Statistics online or published reports }\end{array}$ & $\begin{array}{l}\text { Little information on ethnic minority or } \\
\text { socioeconomic differences. }\end{array}$ \\
\hline CABG surgery patients (number) & $\begin{array}{l}\text { CABG numbers from 1991-2000 available online on UK } \\
\text { Society for Cardiothoracic Surgeons of Great Britain and } \\
\text { Ireland's web site (http://www.scts.org/doc/2102). } .^{19} \text { To } \\
\text { obtain figures for England and Wales CABG numbers for } \\
\text { Scotland and Ireland deducted from UK figures. }\end{array}$ & $\begin{array}{l}\text { Appear accurate. Lack detail on age, } \\
\text { sex, ethnic group, social status, and } \\
\text { long term survival. }\end{array}$ \\
\hline Angioplasty patients (number) & $\begin{array}{l}\text { Angioplasty numbers for 1991-2000 available online on } \\
\text { British Cardiovascular Intervention Society's web site } \\
\text { http://www.bcis.org.uk/audit/Bcis00.ppt. }\end{array}$ & $\begin{array}{l}\text { Age and sex split not provided. No long } \\
\text { term outcomes. }\end{array}$ \\
\hline Angina patients admitted to hospital (number) & $\begin{array}{l}\text { Number of angina patients admitted to hospital available } \\
\text { from Hospital Episode Statistics 1999-2000 } \\
\text { (http://www.doh.gov.uk/hes/index.html). }{ }^{21}\end{array}$ & $\begin{array}{l}\text { Episodes not individuals. Coding } \\
\text { accuracy improving. Lack detail on } \\
\text { subgroups. No data on therapy. }\end{array}$ \\
\hline Angina patients in the community (number) & $\begin{array}{l}\text { Prevalence of "ever experienced angina" is available from } \\
\text { Health Survey for England 1998, }{ }^{16} \text { and British Regional } \\
\text { Heart Study. }{ }^{68}\end{array}$ & Only prevalence not incidence. \\
\hline Heart failure patients admitted to hospital (number) & $\begin{array}{l}\text { Number of heart failure patients admitted to hospital } \\
\text { available from Hospital Episode Statistics 1999-2000 } \\
\text { (http://www.doh.gov.uk/hes/index.html) }\end{array}$ & As for angina admissions. \\
\hline Heart failure patients in the community (number) & $\begin{array}{l}\text { Prevalence of treated heart failure patients in the } \\
\text { community available from Key Health Statistics from } \\
\text { General Practice } 1998 \text { report }^{13}\end{array}$ & $\begin{array}{l}\text { GP consultations; therefore omits } \\
\text { subjects not presenting to NHS. }\end{array}$ \\
\hline
\end{tabular}

of the studies for their methodology), ease of access (availability of information either published or electronically), and inclusion of information on age and sex breakdowns, ethnic, and socioeconomic categories.

\section{RESULTS}

\section{Population and patient data sources}

Table 1 gives the main data sources for population and patient data.

Data from ONS official statistics ${ }^{618}$ were easily accessible both electronically and in published form. The British Heart Foundation provided another very useful source of annually updated CHD statistics for the UK. ${ }^{2}$

Information on patient numbers undergoing CABG surgery has been available from the United Kingdom Cardiac Surgical Register since 1977. ${ }^{19}$ The register was based on voluntary and anonymous reporting of activity and hospital mortality for $\mathrm{CABG}$, valvular, and congenital heart disease surgical procedures performed in NHS hospitals. Each unit was asked to return a standard questionnaire annually to the Society of Cardiothoracic Surgeons. ${ }^{19}$ These data were then analysed and published as annual reports. However, while reasonably complete, the register lacks details on age, sex, ethnicity, social status, and longterm survival.

Angioplasty patient numbers have been available from the British Cardiovascular Intervention Society's Audit returns since $1989 .{ }^{20}$ These referred to angioplasty activity in all interventional centres in the UK, both NHS and private. The data had details on procedures and success, but lacked details on age, sex, and other individual specific information.

The number of acute myocardial infarction, angina, and heart failure patients admitted to hospitals was available from Hospital Episode Statistics (HES) ${ }^{21}$ HES provided information on inpatient care delivered by NHS hospitals in England since 1989. HES collected almost 12 million records per year, and each record contained over 50 items of information. As these records related to named individuals, direct access was prevented by the need to preserve confidentiality. The database contained information on diagnoses, operations, admission method, patients' age, sex and ethnic group, length of stay, waiting time, maternity care, psychiatric care, Healthcare Resource Groups (HRGs), NHS Trusts, and health authority areas. ${ }^{21}$ However, HES could not provide details of the drugs used in hospitals, nor information concerning outpatients or patients treated in accident and emergency departments and then discharged home immediately. HES records described episodes of continuous inpatient care under the same consultant. ${ }^{21}$ In cases where responsibility for a patient's care transferred to a another consultant, there would be two or more records for the same patient. In 1999-2000, about $8 \%$ of spells fell into this category. ${ }^{22}$ Another important limitation of the database was being unable to distinguish between first admissions and readmissions.

The number of angina patients in the community could be estimated using the prevalence of "ever experienced angina", available from the Health Survey for England '98. ${ }^{16}$ This was a series of annual surveys about the health of people in England carried out since 1991. The Health Survey for England contained a "core", which was repeated each year, and each survey year has one or more modules on subjects of special interest. The Health Survey for England 1993, 1994, and 1998 had cardiovascular disease modules and could therefore provide useful information on CHD, stroke, hypertension, and other cardiovascular risk factors.

The number of heart failure patients in the community was principally estimated using prevalence of "treated heart failure" from Key Health Statistics from the General Practice Research Database, $1998 .^{13}$ This report gave the prevalence of various morbidities and treatment data derived from general practitioner medical records. It provided data for age-sex groups. However, as this source was based on general practitioner consultations, it omitted those symptomatic subjects who did not present to the NHS, but who would be detected by epidemiological surveys. ${ }^{23}{ }^{24}$ 
Table 2 Data sources on treatment for CHD in primary care and secondary care in the UK, 1981-2000

\begin{tabular}{|c|c|c|}
\hline Information & Source & Quality and comments \\
\hline \multicolumn{3}{|l|}{ Initial treatments for acute myocardial infarction } \\
\hline Community CPR & $\begin{array}{l}\text { Estimated using data from UK Heart Attack Study, }{ }^{11} \\
\text { UK MONICA registers }{ }^{69} \text { and Scottish Heartstart. } \\
\text { Number of myocardial infarction admissions to } \\
\text { hospital obtained from HES. }\end{array}$ & Ad hoc surveys and ambulance data only. \\
\hline Hospital CPR & $\begin{array}{l}\text { Number of hospital CPR patients estimated using } \\
2000 \text { HES data and The United Kingdom Heart } \\
\text { Attack Study Collaborative Group, }{ }^{12} \text { BRESUS Study }{ }^{25} \\
\text { and UK MONICA registers. }{ }^{69}\end{array}$ & Isolated surveys only. \\
\hline $\begin{array}{l}\text { Thrombolysis } \\
\text { Aspirin } \\
\beta \text { blocker } \\
\text { ACE inhibitor }\end{array}$ & $\begin{array}{l}\text { The United Kingdom Heart Attack Study } \\
\text { Collaborative Group, }{ }^{12} \text { Nottingham Heart Attack } \\
\text { Register. }{ }^{1071} \text { UK MONICA centres in Glasgow and } \\
\text { Belfast reported data on drugs and procedures in MI } \\
\text { (before the event, during the event and post-event) } \\
\text { between 1985-1995. }\end{array}$ & $\begin{array}{l}\text { Isolated surveys, plus some data on numbers } \\
\text { given thrombolysis. Routine information on } \\
\text { hospital treatments for acute myocardial } \\
\text { infarction not available. }\end{array}$ \\
\hline \multicolumn{3}{|l|}{$\begin{array}{l}\text { Secondary prevention after acute myocardial } \\
\text { infarction, CABG surgery, or angioplasty }\end{array}$} \\
\hline $\begin{array}{l}\text { Aspirin } \\
\beta \text { blockers } \\
\text { ACE inhibitors } \\
\text { Statins } \\
\text { Warfarin } \\
\text { Rehabilitation including exercise }\end{array}$ & $\begin{array}{l}\text { Limited data on secondary prevention from General } \\
\text { Practice Research Database report }{ }^{72} \text { and } \\
\text { EUROASPIRE II Study }\end{array}$ & Isolated surveys and a few ad hoc audits only. \\
\hline Unstable angina in hospital admissions & No routine data on therapy & No routine data. \\
\hline Aspirin for community angina & $\begin{array}{l}\text { Data mainly from a General Practice Research } \\
\text { Database report }{ }^{72}\end{array}$ & Isolated surveys only. \\
\hline Heart failure treatment in hospital admissions & - & Isolated audits only. \\
\hline Heart failure treatment in the community & Key Health Statistics From General Practice $1998^{13}$ & Isolated papers. \\
\hline Treatment of individual patients for hypertension & $\begin{array}{l}\text { British Regional Heart Study }{ }^{34} \text { Caerphilly papers } \\
\text { and the Health Survey for England } 1998^{16}\end{array}$ & $\begin{array}{l}\text { Information limited, especially in the elderly } \\
\text { population. }\end{array}$ \\
\hline
\end{tabular}

\section{Cardiological treatments}

Table 2 gives the data sources on cardiological treatments in primary and secondary level.

The precise number of CHD patients who had cardiopulmonary resuscitation (CPR) in the community (before reaching hospital) was not known, neither was the number of CHD patients who had CPR in hospital. These two figures could only be estimated from various surveys. ${ }^{1125} 26$

Information about hospital admissions in 2000 was available online from HES. ${ }^{21}$ However, trend data, and details of hospital interventions were very limited. Treatment uptake data were not available routinely, coming principally from isolated surveys and registers. For treatment at primary care level, limited prescription and uptake data were available from Prescribing Analysis and Cost Tabulate (PACT), ${ }^{27}$ and a few published local audits and studies. ${ }^{28-32}$ The EUROASPIRE II Study provided treatment levels for secondary care of CHD from a small number of selected UK hospitals, but age and sex breakdowns were not generally available.

Good efficacy data on clinical interventions were generally available from published randomised trials and metaanalyses, and will not be considered further here.

\section{Cardiovascular risk factor data sources}

Table 3 gives the population based cardiovascular risk factor data sources and their evaluations.

The risk factors considered were smoking, total cholesterol levels, blood pressure, physical activity, obesity, diabetes, and deprivation. Population based risk factor data, either distribution (mean, standard deviation) or prevalence, were available principally from the British Regional Heart Study, ${ }^{14} 34$ the General Household Survey, ${ }^{15}$ and the Health Survey for England. ${ }^{16}$ Information was very limited for the 1980s, but more extensive by the year 2000.

Blood pressure data were limited until recent times. The British Regional Heart Study provided some blood pressure data in 1981, but only for men aged 40-59. ${ }^{14}$ The Dietary and Nutritional Survey of British Adults ${ }^{35}$ was another source for blood pressure data from 1990 onwards and provided sex and limited age breakdowns (under 65). The Health Survey For England has included blood pressure data since $1993 .{ }^{36}$

Data on cholesterol levels were very limited during the 1980s. ${ }^{33}$ The Health Survey For England included cholesterol levels from 1993. However, changing laboratory methods used between surveys made the interpretation of recent trends difficult, ${ }^{16}$ even when supported by trend data from the MONICA surveys based in Scotland and Northern Ireland. ${ }^{37}$

Data on obesity (defined as BMI $>30 \mathrm{~kg} / \mathrm{m}^{2}$ ) were available from two Department of Health surveys in the early 1980s. ${ }^{35} 38$ Data on other anthropometric measures such as waist to hip ratio, were not available in early 1980s but only from more recent population surveys. ${ }^{16}$

Some indirect evidence of a decline in physical activity (an increase in car journeys and decrease in miles walked) was available from the Department of Transport's Transport Statistics for Great Britain. ${ }^{39}$ However, no comprehensive population based measures were available before the Allied Dunbar Survey in $1990 .^{40}$ The British Regional Heart Study provided physical activity data limited to men aged 40-59. ${ }^{41}{ }^{42}$ The Health Survey for England included physical activity questions since 1991 with revisions in 1997 and 1998. ${ }^{16}$ Furthermore, definitions of physical inactivity have varied in different surveys ${ }^{14} 1^{40}$ so comparable trend information were generally not available.

Smoking prevalence was the exception among the cardiovascular risk factors with good data trends easily available from successive General Household Surveys ${ }^{15}{ }^{43}$ and the British Household Panel Surveys. ${ }^{44}$ Age, sex, and socioeconomic breakdowns were also available.

There were some studies on diabetes starting from the 1970s, mainly focusing on treatment efficacy (The United Kingdom Prospective Diabetes Study) $)^{45}$ and mortality in 
Table 3 Data sources on cardiovascular risk factors in the UK, 1981-2000

\begin{tabular}{|c|c|c|c|}
\hline \multirow{2}{*}{$\begin{array}{l}\text { Cardiovascular risk } \\
\text { factors Information }\end{array}$} & \multicolumn{2}{|l|}{ Source } & \multirow[b]{2}{*}{ Evaluation } \\
\hline & Initial year (1981) & Most recent year (2000) & \\
\hline Population blood pressure & $\begin{array}{l}\text { The Dietary and Nutritional } \\
\text { Survey of British Adults } s^{35} \text { and } \\
\text { British Regional Heart Study }\end{array}$ & Health Survey for England $1998^{16}$ & $\begin{array}{l}\text { Blood pressure data very limited until recent times. } \\
\text { For early years The Dietary and Nutritional Survey of } \\
\text { British Adults and British Regional Heart Study (only } \\
\text { for men) provided mean blood pressure levels. } \\
\text { Health Survey for England included these data since } \\
1993 \text {. }\end{array}$ \\
\hline Smoking prevalence & $\begin{array}{l}\text { General Household Survey } \\
1980,{ }^{15} \text { British Household Panel } \\
\text { Survey }^{44}\end{array}$ & $\begin{array}{l}\text { General Household Survey } 2000,{ }^{43} \\
\text { British Household Panel Survey }{ }^{44}\end{array}$ & $\begin{array}{l}\text { Good data for trends in smoking prevalence } \\
\text { categorised by age and sex easily available from } \\
\text { General Household Surveys and British Household } \\
\text { Panel Survey. }\end{array}$ \\
\hline Cholesterol & British Regional Heart Study ${ }^{14}$ & $\begin{array}{l}\text { Cholesterol levels measured in } \\
\text { Health Survey for England } 1994 \\
\text { and 1998. }{ }^{16} \text { MONICA Glasgow } \\
\text { and Belfast trends 1985-1995 } \\
\text { available for comparison (personal } \\
\text { communication). }\end{array}$ & $\begin{array}{l}\text { Limited data available for the early 1980s. } \\
\text { Changing laboratory methods used in the Health } \\
\text { Survey for England (1994-1998) made } \\
\text { interpretation of recent trends difficult, even when } \\
\text { supported by trends from UK MONICA surveys. }\end{array}$ \\
\hline Obesity & $\begin{array}{l}\text { The Heights and Weights of } \\
\text { Adults in Great Britain } \\
{ }^{38}\end{array}$ & Health Survey for England $98^{16}$ & $\begin{array}{l}\text { Data on mean BMI and obesity (defined } \mathrm{BMI}>30 \text { ) } \\
\text { available from two DoH surveys in early } 1980 \text { s. } \\
\text { Data on other anthropometrical measures, for } \\
\text { example, waist to hip ratio, were not available in } \\
\text { early } 1980 \text { s but these data available from some } \\
\text { more recent population surveys (Health Survey for } \\
\text { England). }\end{array}$ \\
\hline Physical activity & British Regional Heart Study ${ }^{14}$ & Allied Dunbar Survey $1990^{40}$ & $\begin{array}{l}\text { No comprehensive population based measures were } \\
\text { available before Allied Dunbar Survey } 1990 \text {. British } \\
\text { Regional Heart Study data limited to men aged } \\
40-59 \text {. Definitions of physical inactivity varied in } \\
\text { different surveys }{ }^{14} 1640 \text { so comparable trend } \\
\text { information not available directly. Some indirect } \\
\text { evidence of a decline in physical activity available } \\
\text { from Department for Transport's Transport Statistics } \\
\text { for Great Britain report. }{ }^{39}\end{array}$ \\
\hline Diabetes & Poole Diabetes Study ${ }^{47}$ & $\begin{array}{l}\text { Health Survey for England 98, } \\
\text { General Practice Research } \\
\text { Database }^{74}\end{array}$ & $\begin{array}{l}\text { Data on diabetes prevalence are either not available } \\
\text { or not comparable for early } 1980 \text { s. Lately trend } \\
\text { information is available from Health Survey for } \\
\text { England and General Practice Research Database } \\
\text { this latter may overestimate trend. }\end{array}$ \\
\hline Deprivation & 1981 Census data & 2001 Census data awaited & $\begin{array}{l}\text { Standardised trend data for deprivation score not } \\
\text { available. Information available on: household } \\
\text { income, adjusted for tax and benefits, housing } \\
\text { tenure. }\end{array}$ \\
\hline
\end{tabular}

diabetic patients (British Diabetic Association Cohort Study). ${ }^{46}$ However, early information on trends in diabetes prevalence was available only from one population survey in Poole starting in 1983. ${ }^{47}$ The Health Survey for England provided self reported information on diabetes prevalence since 1991. ${ }^{36}$ Trends in general practice consultations between 1994 and 1998 recently became available from the General Practice Research Database. ${ }^{48}$

Socioeconomic information was available on household income, adjusted for tax and benefits, and housing tenure from various sources including Social Trends ${ }^{49}$ and the General Household Survey. ${ }^{15}{ }^{43}$ However, because deprivation scores describe relative deprivation on the basis of cross sectional data, trend data for deprivation scores have not been generated. Data on socioeconomic characteristics, defined as occupation of head of household, equalised income, and health authority area type were available from the Health Survey for England. ${ }^{16}$ The Health Survey for England 1999 focused on ethnic minority groups in England, and provided some relevant data for these groups. ${ }^{50}$

\section{DISCUSSION}

Available information on CHD in the UK is frequently patchy, obsolete, or simply not available. Although routinely collected data provide large quantities of health information, often covering the whole population over a long period of time, such sources have limitations and are underused. ${ }^{51}$ The Office for
National Statistics provides useful updated population and mortality statistics. Much of the Office for National Statistics information is available electronically, which makes it much more accessible for users. Likewise Hospital Episode Statistics, which summarise admissions to the NHS hospitals, but which lack detail on interventions.

Public health information on coronary heart disease in England must be improved. At present, the NHS annually spends over $£ 2$ billion on a range of evidence based initiatives for the treatment of CHD. However, evaluation of these initiatives using existing routine data is simply not possible. Furthermore, monitoring this common and devastating disease is generally confined to analysis of mortality statistics. Over 35000 CABG operations are performed each year, however survival even two years later is not routinely available..$^{52}$ Thirty day case fatality after admission for acute myocardial infarction or CABG surgery have been used as Department of Health performance indicators. ${ }^{53}$ However, variations in performance indicators between individual hospitals are vulnerable to differences in coding practices and case mix. $^{54}$

To review CHD data sources in all countries is beyond the scope of this paper; however, some international comparisons are extremely useful. Northern European countries have developed and implemented better CHD monitoring systems.

CHD mortality rates in Finland were once the highest in the world. ${ }^{55}$ A series of regional risk factor surveys (FINRISK) 


\section{Key point}

- The quality of UK data on coronary heart disease is remarkably patchy and poor despite coronary heart disease being the largest cause of death.

have been carried out there every five years since the early 1970 s. $^{556}$ These use a standardised methodology, include all the important CHD risk factors, with high participation rates and a large sample size (about 14000 for the 2002 survey). Reliable estimates of trends and their contributions to CHD mortality declines can therefore be made over a 30 year period. These surveys also permit comparatively quick identification of adverse developments such as the increase in smoking among women. ${ }^{57-59}$

Monitoring of risk factors and of secular trends in risk factor epidemiology is also available in Norway. ${ }^{60}$ Cardiovascular risk factor studies have been conducted in different regions since the late 1950s. Since the 1970s, the National Health Screening Service (SHUS) cardiovascular disease screening and prevention programmes visit all municipalities every three years, and achieve high response rates. ${ }^{60}$

In the USA, the National Health and Nutrition Examination Survey (NHANES) has been periodically conducted since the early 1960 s to obtain nationally representative information on health, nutritional status, risk factors, and health behaviours in the population. NHANES III (1988-94) is the seventh of these. ${ }^{61}$

The Information and Statistics Division (ISD) in Scotland collects good data on all patients treated for CHD and the procedures received. Scotland's routine NHS data are of high quality and data linkage permits the investigation of the epidemiology and treatment of heart disease across the population, with comprehensive analyses then being possible on different forms of the disease, including myocardial infarction and heart failure. ${ }^{62-64}$

In England and Wales, the CHD NSF, NHS Plan, and CHD Information Strategy now explicitly recognise the huge importance of disease monitoring and service evaluation. All have made a number of specific and sensible recommendations. However, at present over $99 \%$ of the $£ 2$ billion NHS CHD budget is spent on medical interventions, particularly revascularisation. Less than $1 \%$ is currently spent on the monitoring of CHD. ${ }^{24}$ These are inadequate resources for even basic information strategy or information technology. Periodical surveys could provide valuable information about the risk factor trends in the population. In addition, a system of disease registers of individual data, which can be linked, as in some Scandinavian countries would help to detail medical interventions and monitor their effectiveness. Furthermore, although some national data collections (such as the Health Survey for England) can support the Information Strategy, such datasets are not "locally owned" and lack the scope to analyse specific population groups, such as ethnic minorities. ${ }^{65}$

\section{CONCLUSION}

Future CHD disease monitoring and evaluation will require comprehensive and accurate population based information on trends in patient numbers, treatment uptake, and risk factors. This will require adequate resources to improve existing information systems. Regular and comprehensive surveys (including women, elderly people, and ethnic groups), using standardised methodology will also be essential. Until then, there is a very real risk that NHS CHD strategies will blunder in the dark.

\section{Authors' affiliations}

B Unal, J A Critchley, S Capewell, Department of Public Health, Liverpool University, Liverpool, UK
B Unal, Department of Public Health, School of Medicine, Dokuz Eylul University, Izmir, Turkey

Funding: Belgin Unal was funded by a North West Regional Research and Development Training Fellowship.

\section{REFERENCES}

1 Critchley J, Capewell S. Why model coronary heart disease? Eur Heart J 2002;23:1 10-16.

2 British Heart Foundation Statistics Database. Coronary heart disease statistics, 2002. http://www.dphpc.ox.ac.uk/bhfhprg/stats/2000/ 2002/index.html (Accessed 25 Jun 2002).

3 Department of Health. National Service Framework for coronary heart disease. London: Department of Health, 2000.

4 Department of Health. Coronary Heart Disease Information Strategy, 2001. http://www.doh.gov.uk/ipu/strategy/nsf/chdisdoc.pdf (Accessed 17 June 2002).

5 Aslan B, Critchley J, Capewell S. Explaining the decline in coronary heart disease mortality in England and Wales, 1981-2000. [Abstract]. J Epidemiol Community Health 2002;56 (suppl 2):A9.

6 ONS, Office for National Statistics. Deaths, 2000 registrations: Death by age, sex and underlying cause, England and Wales. Health Statistics Quarterly 2001;10:60-6.

7 EUROASPIRE Study Group. A European Society of Cardiology survey of secondary prevention of coronary heart disease: principal results. Eur Heart J 1997;18:1569-82.

8 Bowker TJ, Clayton TC, Ingham J, et al. A British Cardiac Society survey of the potential for the secondary prevention of coronary disease: ASPIRE (Action on Secondary Prevention through Intervention to Reduce Events). Heart 1996;75:334-42.

9 EUROASPIRE Study Group. Lifestyle and risk factor management and use of drug therapies in coronary patients from 15 countries; principal results from EUROASPIRE II Euro Heart Survey Programme. Eur Heart $J$ 2001;22:554-72.

10 Brown N, Young T, Gray D, et al. Inpatient deaths from acute myocardial infarction, 1982-92: analysis of data in the Nottingham heart attack register. BN 1997;315:159-64

11 Norris RM. Fatality outside hospital from acute coronary events in three British health districts, 1994-5. United Kingdom Heart Attack Study Collaborative Group. BM 1998;316:1065-70.

12 The United Kingdom Heart Attack Study (UKHAS) Collaborative Group. Effect of time from onset to coming under care on fatality of patients with acute myocardial infarction: effect of resuscitation and thrombolytic treatment. Heart 1998;80:114-20.

13 Office for National Statistics. Key health statistics from general practice 1998. London: National Statistics, 2000. MB6 No.2.

14 Shaper AG, Pocock SJ, Walker M, et al. British Regional Heart Study: cardiovascular risk factors in middle-aged men in 24 towns. BM 1981;283:179-86.

15 ONS, Office for National Statistics-Social Survey Division. General Household Survey 1980. London: Stationery Office, 1982.

16 Erens B, Primatesta P. Health survey for England. Cardiovascular disease '98. London: Stationery Office, 1999

17 Last J. A dictionary of epidemiology. Oxford: Oxford University Press, 1988.

18 ONS, Office for National Statistics. Population: age and sex, 1971 onwards. Health Statistics Quarterly 2001;11

19 Society of Cardiothoracic Surgeons of Great Britain and Ireland. Trends in surgery for ischaemic heart disease. http://www.scts.org/doc/ 2102 (Accessed 19 Jun 2002).

20 de Belder M. British Cardiac Intervention Society (BCIS) audit returns of interventional procedures 2000. http://www.bcis.org.uk/audit/ Bcis00.ppt (Accessed 19 Jun 2002).

21 Department of Health. NHS Hospital in-patient data for the period 1999-2000 based on Hospital Episode Statistics (HES). http://www.doh.gov.uk/hes/index.html (Accessed 19 Jun 2002).

22 Department of Health. Glossary of terms- Hospital in patient data based on HES data. http://www.doh.gov.uk/hes/site_help/glossary/ index.html (Accessed 19 Jun 2002).

23 McDonagh TA, Morrison CE, Lawrence A, et al. Symptomatic and asymptomatic left-ventricular systolic dysfunction in an urban population. Lancet 1997;350:829-33

24 Morgan S, Smith H, Simpson I, et al. Prevalence and clinical characteristics of left ventricular dysfunction among elderly patients in general practice setting: cross sectional survey. BM 1999;318:368-72.

25 Tunstall-Pedoe H, Bailey L, Chamberlain DA, et al. Survey of 3765 cardiopulmonary resuscitations in British hospitals (the BRESUS Study): methods and overall results. BM 1992;304:1347-51.

26 Pell JP, Sirel J, Marsden AK, et al. Sex differences in outcome following community-based cardiopulmonary arrest. Eur Heart J 2000;21:239-44.

27 NHS Precription Pricing Authority. PACT pages- Cardiovascular prescribing. http://www.ppa.org.uk/news/pact-012002.htm (Accessed 19 Jun 2002)

28 Birkhead JS. Trends in the provision of thrombolytic treatment between 1993 and 1997. Myocardial Infarction Audit Group. Heart 1999;82:438-42.

29 Clarke KW, Gray D, Hampton JR. Evidence of inadequate investigation and treatment of patients with heart failure. Br Heart J 1994;71:584-7.

30 Freemantle N, Mason J, Eccles M. Audit of use of ACE inhibitors and monitoring in general practice. Guidelines on monitoring, on their own, are not sufficient. BM 1999;318:1697. 
31 Whitford DL, Southern AJ. Audit of secondary prophylaxis after myocardial infarction. BM 1994;309:1268-9.

32 Stewart S, Jenkind A, Buchan S, et al. The current cost of heart failure to the National Health Service in the UK. European Journal Heart Failure 2002:4:361-71.

33 Thelle DS, Shaper AG, Whitehead TP, et al. Blood lipids in middle-aged British men. Br Heart J 1983;49:205-13.

34 Shaper AG, Ashby D, Pocock SJ. Blood pressure and hypertension in middle-aged British men. J Hypertens 1988;6:367-74.

35 OPCS, Office of Population Censuses and Surveys. The dietary and nutritional survey of British adults. London: HMSO, 1990.

36 Bennet N, Dodd T, Platley J, et al. Health Survey for England 1993. London: HMSO, 1995.

37 Kuulasmaa K, Tunstall PH, Dobson AJ, et al. Estimation of contribution of changes in classic risk factors to trends in coronary-event rates across the WHO MONICA Project. Lancet 2000;355:675-87.

38 OPCS, Office of Population Censuses and Surveys- Social Survey Division. The heights and weights of adults in Great Britain. London: Stationery Office, 1984.

39 Department for Transport. Transport statistics Great Britain: 2001 edition. London: The Stationery Office, 2001.

40 The Sports Council and the Health Education Authority. Allied Dunbar National Fitness Survey. London: Belmont Press, 1992.

41 Shaper AG, Wannamethee G. Physical activity and ischaemic heart disease in middle-aged British men. Br Heart J 1991;66:384-94.

42 Wannamethee G, Shaper AG. Physical activity and stroke in British middle aged men. BM 1992;304:597-601.

43 ONS, Office for National Statistics Social Survey Division. Living in Britain: results from the 2000/01 General Household Survey. London: The Stationery Office, 2001.

44 Institute for Social and Economic Research (ISER). British Household Panel Survey. 1991. http://www.iser.essex.ac.uk/bhps/index.php (Accessed 27 Jun 2002).

45 American Diabetes Association. Implications of the United Kingdom Prospective Diabetes Study. Diabetes Care 2002;25:S28-32.

46 Laing SP, Swerdlow SD, Slater SD. The British Diabetic Association Cohort Study, II: cause specific mortality in patients with insulin-treated diabetes mellitus. Diabet Med 1999;16:466-71.

47 Gatling W, Budd S, Walters D, et al. Evidence of an increasing prevalence of diagnosed diabetes mellitus in the Poole area from 1983 to 1996. Diabet Med 1998;15:1015-21

48 Ryan R, Newnham A, Khunti K, et al. Prevalance of of known diabetes mellitus in general practice in England and Wales 1994-1998. J Epidemiol Community Health 2002;56 (suppl 2):A7.

49 Matheson J, Summerfield C. Social Trends 30, 2000 edition. Office for National Statistics. London: Stationery Office, 2000

50 Erens B, Primatesta P, Prior G, eds. Health Survey for England-the health of minority ethnic groups 99. London: The Stationery Office, 2001

51 Bain MR, Chalmers JW, Brewster DH. Routinely collected data in national and regional databases - an under- used resource. J Public Health Med 1997;19:413-18

52 Pell JP, Walsh D, Norrie J, et al. Outcomes following coronary artery bypass grafting and percutaneous transluminal coronary angioplasty in the stent era: a prospective study of all 9890 consecutive patients operated on in Scotland over a two year period. Heart 2001;85:662-6.

53 Department of Health. NHS performance endicators: February 2002. http://www.doh.gov.uk/nhsperformanceindicators/2002/technical.html (Accessed 28 Jun 2002).

54 Majeed FA, Voss S. Performance indicators for general practice. BM 1995;311:209-10
55 Vartiainen $\mathbf{E}$, Jousilahti $\mathrm{P}$, Alfthan $\mathrm{G}$. Cardiovascular risk factor changes in Finland, 1972-1997. Int J Epidemiol 2000;29:49-56.

56 Vartiainen E, Puska P, Pekkanen J, et al. Changes in risk factors explain changes in mortality from ischaemic heart disease in Finland. BM 1994;309:23-7.

57 Salonen JT. Prevention of coronary heart disease in Finlandapplication of the population strategy. Ann Med 1991;23:607-12.

58 Vartiainen E, Korhonen HJ, Pietinen P, et al. Fifteen-year trends in coronary risk factors in Finland, with special reference to North Karelia. Int J Epidemiol 1991;20:651-62.

59 Vartiainen E, Puska P, Jousilahti P, et al. Twenty-year trends in coronary risk factors in north Karelia and in other areas of Finland. Int J Epidemio 1994;23:495-504.

60 Bjartveit K, Wøien G. Cardiovascular disease risk factors in Norway. Oslo: SUSH, 1997.

61 US Department of Health and Human Services. Plan and operation of the third National Health and Nutrition Examination Survey, 1988-1994. Vital Health Stat 1994.

62 Capewell S, Maclntyre K, Stewart S, et al. Age, sex, and social trends in out-of-hospital cardiac deaths in Scotland 1986-95: a retrospective cohort study. Lancet 2001;358:1213-17.

63 Maclntyre K, Capewell S, Stewart S, et al. Evidence of improving prognosis in heart failure. Trends in case fatality in 66547 patients hospitalized between 1986 and 1995. Circulation 2000;102:1126-31.

64 Maclntyre K, Stewart S, Chalmers J, et al. Relation between socioeconomic deprivation and death from a first myocardial infarction in Scotland: population based analysis. BM 2001;322:1 152-3

65 Association of Public Health Observatories. The role of Public Health Observatories in implementing the Coronary Heart Disease National Service Framework. Report of a workshop held by Association of Public Health Observatories. http://www.sepho.org.uk/heartdisease/ CHD_NSF.pdf (Accessed 26 Feb 2001.)

66 OPCS, Office of Population Censuses and Surveys England and Wales. Mortality Statistics 1981 cause. Review of the Registrar General on deaths by cause, sex and age, in England and Wales, 1981. London: Stationery Office, 1981

67 ONS, Office for National Statistics. Mortality Statistics cause. Review of the Registrar General on deaths by cause, sex and age, in England and Wales, 1999. London: Stationery Office, 2000.

68 Lampe FC, Whincup PH, Wannamethee SG, et al. The natural history of prevalent ischaemic heart disease in middle-aged men. Eur Heart $J$ 2000;21:1052-62

69 Mähönen M, Zygimantas C, Kuulasmaa K. MONICA acute coronary care data book 1981-1995. Helsinki: World Health Organisation (WHO) and the WHO MONICA Project investigators, 2001.

70 Sedgwick ML, Dalziel K, Watson J, et al. Performance of an established system of first responder out-of-hospital defibrillation. The results of the second year of the Heartstart Scotland Project in the 'Utstein Style'. Resuscitation 1993;26:75-88.

71 Rowley JM, Mounser P, Harrison EA, et al. Management of myocardial infarction: implications for current policy derived from the Nottingham Heart Attack Register. Br Heart J 1992;67:255-62.

72 Ryan R, Majeed A. Prevalence of ischaemic heart disease and its management with statins and aspirin in general practice in England and Wales, 1994-98. Health Statistics Quarterly 2001:12:34-9.

73 The Caerphilly and Speedwell Collaborative Group. Caerphilly and Speedwell collaborative heart disease studies. J Epidemiol Community Health 1984;38:259-62.

74 Gray J, Majeed A, Kerry S, et al. Identifying patients with ischaemic heart disease in general practice: cross sectional study of paper and computerised medical records. BN 2000;321:548-50. 